\title{
Factors Accelerating Recovery of Intestinal Motility after Radical Cystectomy with Urinary Diversion
}

\author{
MOHAMED A. REFAT, M.Sc.; TAREK A. GAMEEL, M.D.; MOHAMED A. OMAR, M.D.; \\ AYMAN A. HASSAN, M.D. and MOHAMED A. ELBENDARY, M.D.
}

The Department Urology, Tanta University, Tanta, Egypt

\begin{abstract}
Background: Radical cystectomy (RC) with urinary tract reconstruction currently remains the gold standard treatment for invasive bladder cancer. RC associated with many complications, postoperative ileus is the most common one which lead to increasing length of hospital stay. Multiple perioperative care plans was put aimed to decrease POI.
\end{abstract}

Aim of Study: Evaluation of the different factors that can help to accelerate recovery of intestinal motility after radical cystectomy and urinary diversion in order to decrease the length of hospital stay.

Patients and Methods: A total of 37 patients who underwent radical cystectomy with urinary diversion using intestinal segments were divided into 2 groups. In group A $(n=23)$, our new protocol of perioperative preparation applied, in group $B(n=14)$ classic way of perioperative preparation applied. The main differences between both ways are one day intestinal preparation with use of fortrans preoperative, anal dilatation intraoperative and chewing gums postoperative.

Results: There was statistical significance in first intestinal sound first passage of flatus, beginning of soft diet, time to regular diet and hospital stay in favor of group A as compared to the group B ( $p$-value $<0.05)$.

Conclusion: Application of our protocol decrease postoperative ileus, more rapid time for regular diet and decrease hospital stay after radical cystectomy with urinary diversion.

Key Words: Radical cystectomy - Postoperative Ileus (POI) - Length of hospital stays (LOS).

\section{Introduction}

RADICAL cystectomy represents the standard treatment for muscle invasive bladder cancer and recurrent, high-grade, superficial transitional cell carcinoma (TCC) not controlled by conventional therapy $[\mathbf{1 , 2}]$.

Correspondence to: Dr. Mohamed A. Refat, E-Mail: dr.m7mdref3t@yahoo.com.
It is recognized as a major operative procedure that carries the potential for serious complications $[3,4]$.

Intestinal urinary reconstruction generally follows cystectomy, with a consequent increase in the burden of the procedure; hence attentive perioperative preparation is critical [5].

When co-morbid conditions are frequently present (e.g., coronary artery disease, DM) further emphasizing the importance of perioperative and surgical management $[6,7]$.

The mortality and morbidity inherent to the procedure are expectedly high and although advances in perioperative medical care, anesthetic management and surgical techniques have lowered mortality to less than $3 \%$ the early postoperative morbidity rate (i.e. within 30 days) exceed $30 \%$ $[2,4,7]$

Also postoperative complications result in prolonged hospitalization with greater mortality and morbidity are observed in the elderly [6-11]. A delayed return of bowel function attributable to postoperative ileus stands out as one of the most frequent causes of increased length of hospital stay (LOS), in abdominal general surgery series $[12,13]$ and radical cystectomy series $[\mathbf{4 , 5 , 7 ]}$.

In recent years, there has been interest from various sources in the use of standardized health care strategies in an attempt to reduce variation, improve quality of care, and decrease the LOS for major surgical [12-14] and urologic [15-19] . procedures.

In this prospective study we evaluated the different factors that can help to accelerate recovery of intestinal motility after radical cystectomy and 
urinary diversion in order to decrease the length of hospital stay.

\section{Patients and Methods}

It is prospective study conducted on patients with muscle invasive bladder cancer who underwent radical cystectomy with intestinal urinary diversion with new way of intestinal preparation in urology department Tanta University from January 2017 to December 2017.

A total of 37 patients who underwent radical cystectomy with urinary diversion using intestinal segments were divided into 2 groups. In group A $(n=23)$, our new protocol of perioperative preparation applied, in group B $(n=14)$ classic way of perioperative preparation applied. Our study was approved by the local Ethics and Research Committee at Tanta Faculty of Medicine under number 31394/12/16; informed consent was obtained from all participants before enrollment in the study.

Our new protocol consists of preoperative, intraoperative, and postoperative measures as follow:

\section{A- Preoperative measures:}

Only 1 enema afternoon before surgery, Patients were given Fortrans (polyethylene glycol Macrogol 4000) (its composition is Macrogol, Potassium chloride, sodium chloride, sodium bicarbonate and sodium sulfate anhydrous) sachet on one liter water swollen throughout the day before surgery and were allowed to have a light lunch with soft food and fluids the evening before surgery, and fasting starting at midnight.

\section{$B$ - Intraoperative measures:}

Nasogastric tube insertion at the beginning of procedure, administration of second-generation cephalosporins was started on the morning of surgery, renewed after the first 2 hours of the procedure, and maintained until removal of the surgical drains, combined general and epidural anesthesia was given, two layers closure of the bowel with tension free sutures using polyglactin 910 (Vicryl) 4/0 sutures, anal dilatation at the end of the operation by the assistant.

\section{C-Postoperative measures:}

Nasogastric tube removed after 4-6 hours of the surgery, parenteral nutrition will be started the day of operation, chewing gum was started in the first morning after surgery, once audible bowel sounds confirmed, we started oral fluids only, second day after bowel sounds are confirmed, we will start soft foods orally, once passage of stool occurred at any time, we stopped parentral nutrition and start ordinary diet.

The classic way of preparation differs from our new way in the following:

\section{A- Preoperative measures:}

3 days intestinal preparation; 3 days before operation soft diet and oral fluids are only allowed, 2 days before operation only oral fluids is allowed and the day before operation complete fasting for 24 hours, 2 times enema done 2 days before operation and 4 times enema done the day before operation, no Fortrans was given to the patients.

\section{B-Intraoperative measures:}

No anal dilatation was done.

\section{C-Postoperative measures:}

No chewing gum was given, oral fluids were started at least after 3 days after operation even the flatus was passed earlier.

Number of patients: 37 patients.

\section{Patient selection:}

\section{A-Inclusion criteria:}

Patients who are candidates for radical cystectomy for bladder cancer with curative intent and intestinal urinary reconstruction (orthotopic or heterotopic neobladders, ileal conduits).

\section{$B$ - Exclusion criteria:}

1- Patients with history of pelvic radiation.

2- Patient who will undergo radical cystectomy with no use of bowel segments.

3- Patients known to have GIT disease (eg, ulcerative colitis, Chron's disease).

\section{Statistical analysis:}

Statistical analysis was done using IBM SPSS software version 20.0. (Armonk, NY: IBM Corp). Categorical variables were compared with the chisquared test and numerical variables were compared with ANOVA test. $p<0.05$ was considered statistically significant.

\section{Results}

This study was conducted on twenty three patients who underwent radical cystectomy with urinary diversion using intestinal segments (group A) with new protocol of preparation and were compared with fourteen patients (group B) who underwent the same operation with classic way of preparation in Urology Department Tanta University Hospital. 
The age of the patients in group A ranged from 46-68 Y with a mean of $58.22 \pm 5.50$ years while in

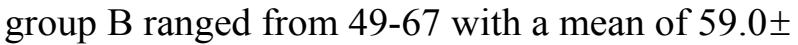
5.94 years. In group A there was 17 males $(73.9 \%)$ and 6 females $(26.1 \%)$ compared to 11 males (78.6\%) and 3 female (21.4\%) in group B with no statically significant difference between both groups as regard age and gender (Table 1).

In group A: 11 patients (47.8\%) underwent ileal conduit urinary diversion and 12 patients $(52.2 \%)$ underwent orthotopic urinary diversion. In group B: 9 patients $(64.3 \%)$ underwent ileal conduit urinary diversion and 5 patients (35.7\%) underwent orthotopic urinary diversion, Operative time ranged from 240-360min with a mean of $306.52 \pm 40.41$ $\mathrm{min}$ and from 240-480min with a mean of 379.29 $\pm 79.47 \mathrm{~min}$ in group A and B respectively with no statically significant difference (Table 2).

Postoperative data: The time for the $1 \mathrm{st}$ intestinal sound ranged from 10.0-24.0 hour with a mean of $17.74 \pm 5.09$ and from 12.0-74.0 hour with a mean of $38.0 \pm 22.33$ in group $A$ and $B$ respectively ( $p$-value ${ }^{\left.0.001^{*}\right)}$, the time for the 1st pass of flatus ranged from 20.0-60.0 hour with a mean of 39.30 \pm 14.73 and from 40.0-96.0 hour with a mean of $62.71 \pm 20.90$ in group A and B respectively ( $p$ value $\left.0.009^{*}\right)$, the time for starting of soft diet ranged from 22.0-62.0 hour with a mean of $41.30 \pm$ 14.73 and from 42.0-98.0 hour with a mean of $64.71 \pm 20.90$ in group A and B respectively ( $p$ value $\left.=0.009^{*}\right)$, the time related to start regular diet ranged from 2.0-5.0 days with a mean of 3.35 \pm 1.15 and from 4.0-8.0 days with a mean of $5.64 \pm 1.08$ in group A and B respectively with ( $p$-value $<0.001$ ) and hospital stay ranged from 6.0-16.0 days with a mean of $11.13 \pm 3.40$ and from 14.0-28.0 days with a mean of $19.71 \pm 4.43$ in group A and B respectively ( $p$-value $<0.001$ ) with statistically significant difference in all parameters (Tables 3,4$)$.

Table (1): Comparison between the two studied groups according to demographic data.

\begin{tabular}{|c|c|c|c|c|c|c|}
\hline & \multicolumn{2}{|c|}{$\begin{array}{c}\text { Group A } \\
(\mathrm{n}=23)\end{array}$} & \multicolumn{2}{|c|}{$\begin{array}{c}\text { Group B } \\
(\mathrm{n}=14)\end{array}$} & $\begin{array}{c}\text { Test } \\
\text { of Sig. }\end{array}$ & $p$ \\
\hline \multicolumn{7}{|l|}{ Age: } \\
\hline Range & \multicolumn{2}{|c|}{$46.0-68.0$} & \multicolumn{2}{|c|}{$49.0-67.0$} & $t=0.407$ & 0.686 \\
\hline Mean \pm SD & \multicolumn{2}{|c|}{$58.22 \pm 5.50$} & \multicolumn{2}{|c|}{$59.0 \pm 5.94$} & & \\
\hline Median & \multicolumn{2}{|l|}{59.0} & \multicolumn{2}{|c|}{60.50} & & \\
\hline Sex: & No. & $\%$ & No. & $\%$ & & \\
\hline Male & 17 & 73.9 & 11 & 78.6 & $\chi^{2}=$ & $\mathrm{FE}_{p}=$ \\
\hline Female & 6 & 26.1 & 3 & 21.4 & 0.103 & 1.000 \\
\hline
\end{tabular}

Table (2): Comparison between the two studied groups according to reconstructive type.

\begin{tabular}{lccccccc}
\hline \multirow{2}{*}{$\begin{array}{l}\text { Reconstructive } \\
\text { type }\end{array}$} & \multicolumn{2}{c}{$\begin{array}{c}\text { Group A } \\
(\mathrm{n}=23)\end{array}$} & & \multicolumn{2}{c}{$\begin{array}{c}\text { Group B } \\
(\mathrm{n}=14)\end{array}$} & $\chi^{2}$ & $p=$ \\
\cline { 2 - 3 } & No. & $\%$ & & No. & $\%$ & & \\
\hline Conduit & 11 & 47.8 & & 9 & 64.3 & 0.302 & 0.582 \\
Orthotropic & 12 & 52.2 & & 5 & 35.7 & & \\
\hline
\end{tabular}

Table (3): Comparison between the two studied groups according to different parameters.

\begin{tabular}{|c|c|c|c|c|}
\hline & $\begin{array}{l}\text { Cases } \\
(\mathrm{n}=23)\end{array}$ & $\begin{array}{l}\text { Control } \\
(\mathrm{n}=14)\end{array}$ & $\mathrm{U}$ & $p$ \\
\hline \multicolumn{5}{|l|}{$\begin{array}{l}\text { 1st Intestinal } \\
\text { sound }(h) \text { : }\end{array}$} \\
\hline Range & $10.0-24.0$ & $12.0-74.0$ & $58.0^{*}$ & $0.001 *$ \\
\hline Mean \pm SD & $17.74 \pm 5.09$ & $38.0 \pm 22.33$ & & \\
\hline Median & 20.0 & 28.0 & & \\
\hline \multicolumn{5}{|l|}{$\begin{array}{l}\text { lst pass of } \\
\text { flatus }(h) \text { : }\end{array}$} \\
\hline Range & $20.0-60.0$ & $40.0-96.0$ & $77.50 *$ & $0.009 *$ \\
\hline Mean \pm SD & $39.30 \pm 14.73$ & $62.71 \pm 20.90$ & & \\
\hline Median & 40.0 & 51.0 & & \\
\hline \multicolumn{5}{|l|}{ Soft diet (h): } \\
\hline Range & $22.0-62.0$ & $42.0-98.0$ & $77.50^{*}$ & $0.009 *$ \\
\hline Mean \pm SD & $41.30 \pm 14.73$ & $64.71 \pm 20.90$ & & \\
\hline Median & 42.0 & 53.0 & & \\
\hline
\end{tabular}

Table (4): Comparison between the two studied groups according to regular diet and hospital stay.

\begin{tabular}{lllll}
\hline & $\begin{array}{l}\text { Cases } \\
(\mathrm{n}=23)\end{array}$ & \multicolumn{1}{c}{$\begin{array}{c}\text { Historical } \\
(\mathrm{n}=14)\end{array}$} & $t$ & $p$ \\
\hline Regular diet $(d):$ & & & & \\
$\quad$ Min. - Max. & $2.0-5.0$ & $4.0-8.0$ & $6.009 *$ & $<0.001 *$ \\
Mean \pm SD. & $3.35 \pm 1.15$ & $5.64 \pm 1.08$ & & \\
Median & 3.0 & 6.0 & & \\
Hospital stay $(d):$ & & & & \\
Min. - Max. & $6.0-16.0$ & $14.0-28.0$ & $6.637^{*}$ & $<0.001 *$ \\
Mean \pm SD. & $11.13 \pm 3.40$ & $19.71 \pm 4.43$ & & \\
Median & 11.0 & 20.0 & & \\
\hline
\end{tabular}

\section{Discussion}

Radical cystectomy with urinary tract reconstruction currently remains the gold standard treatment for invasive bladder cancer [20]

Relative to historical outcomes, it is evident that a structured perioperative care plan results in better outcomes following radical cystectomy. This plan should include preoperative patient preparation, attention to intraoperative measures and postoperative care protocols $[17,21,22]$. Complications following surgery are associated with substantial resource use as manifested by increase length of hospital stay, excess morbidity and mortality and charges attributable to these consequences of treatment [23]. In Egypt, the policy of the health care 
system is to decrease LOS and its cost in a way which not affect the patients care. Thus there is impetus for identification of specific patient parameters and processes of care that may place a patient at greater risk for postoperative complications [24]. According to Pruthi et al., he found that postoperative ileus is the most common cause of prolonged hospitalization [25].

According to Enhanced Recovery After Surgery (ERAS) society recommendations Guidelines for perioperative care after radical cystectomy for bladder cancer, they recommend that no need for classic 3 days mechanical bowel preparation and also no need for preoperative fasting [26]

The PEG-electrolyte lavage solutions are effective lavage agents in preparing the gut as well as for urologic surgery in which bowel is used. The administration of PEG lavage is stopped when the rectal effluent is clear and there is no particulate matter in it or when $4 \mathrm{~L}$ of fluid has been given.

Kenneth I. et al., conducted study on 24 patients who underwent radical cystectomy with ileal conduit urinary diversion using PEG in preoperative preparation. They found that PGE is a safe and effective mechanical bowel preparation. PGE is well tolerated, adequately cleans the bowel, and results in a low incidence of postoperative wound infections and pyelonephritis [27].

About chewing gum post-operative there are multiple studies that demonstrate its effect on bowel motility. Erik J. Kouba et al., conducted study on 102 patients underwent radical cystectomy and urinary diversion for clinically localized bladder cancer. These patients were given chewing gum to begin on postoperative day 1 and compared with a group of 51 patients underwent the same operation, this group served as a comparison (control) group in which no gum was dispensed. The time to flatus was shorter, time to bowel movement was reduced and length of hospital stay was shorter in patients who received gum compared with controls [28].

Anal dilatation (Lord's operation) is used for treatment of anal fissures as it decreases sphincter spasming and thereby restores normal blood supply to the anal mucosa. One of the important indications of Lord's operation is after doing a colostomy for obstruction, or a resection and anastomosis. Position of the patient: Lay him on his back with his legs up in stirrups, and give the table a slight headdown tilt. Anal dilatation is done under general anesthesia at the end of the operation. Mechanism of dilatation: Dilatation must be gentle and con- trolled, start by introducing the index fingers of each hand then gradually insert more fingers putting the strain on the 3 and 9 o'clock, trying to avoid damaging his sphincter at 12 o'clock and 6 o'clock. Dilate gradually for 3 or 4 minutes, so that the fibers of his sphincter are stretched and not torn [30]. However, the role of anal dilatation for prevention of POI is not well established yet. In our patients underwent radical cystectomy, the operative time was long with long exposure to anesthesia and its effect on GIT. In addition urinary diversion following radical cystectomy mostly requires resection and anastomosis of the GIT and also soft diet begins 2-3 days after operation. Therefore, anal dilatation was done at the end of the operation under general anesthesia during wound closure without increasing the operative time. Moreover the procedure is very simple without significant complications and without more cost, more time and it helps passage of the stool postoperative. More studies should be done to know the exact effect of anal dilatation on POI as it is still not clear.

A very recent study by Palumbo V. et al., conducted on 114 consecutive patients treated with open radical cystectomy. A study group of 74 patients with Enhanced Recovery After Surgery pathway was compared with a control group of 40 patients with standard perioperative care. They were compared for recovery of bowel function, measured by resumption of bowel sounds, passage of flatus, and passage of stool. Secondary outcome was rate of overall and major 90-day postoperative complications. They concluded that open RC with ERAS pathway allowed a significantly faster recovery of bowel function with no increase in overall and major 90-day postoperative complications, and 30-day readmission rate compared with standard perioperative care. Perioperative outcomes, such as operative time and blood transfusion rate, were comparable in the 2 groups, whereas blood loss was lower and LOS was shorter in the ERAS group [30]

In the present study our results was comparable with Palumbo V.

Conclusion: Application of our protocol decrease postoperative ileus, more rapid time for regular diet and decrease hospital stay after radical cystectomy with urinary diversion.

\section{References}

1- STEIN J.P., LEISKOWSKY G., COTE R., et al.: Radical cystectomy in treatment of invasive bladder cancer: Longterm results in 1,054 patients. J. Clin. Onco., 119: 666675,2001 
2- DALBAGNI G., GENEGA E., HASHIBE M., et al.: Cystectomy for bladder cancer: A contemporary series. J. Uro., 1165: 1111-1116, 2001.

3- FRAZIER H.A., ROBERTSON J.E. and PAULSON D.F. Complications of radical cystectomy and urinary diversion: A retrospective review of cases in 2 decades. J. Uro., 1148: 140 -145, 1992.

4- CHANG S.S., COOKSON M., BAUMGARTNER R.G. et al.: Analysis of early complications after radical cystectomy: Results of a collaborative care pathway. J. Urol., 167: 2012-2016, 2002

5- CHANG S.S., BAUMGARTNER R.G., WELLS N., et al.: Causes of increased hospital stay after radical cystectomy in a clinical pathway setting. J. Urol., 167: 208211,2002

6- Clark P.E., Stein P.J., Groshen S.G., et al.: Radical cystectomy in the elderly. Cancer, 103: 546-552, 2005.

7- HOLLEMBECK B.K., MILLER D.C., TAUBD, et al.: Identifying risk factors for potentially avoidable complications following radical cystectomy. J. Urol., 174: 12311237,2005

8- SOULIÉ M., STRAUB M., GAMÉ X., et al.: A multicenter study of the morbidity of radical cystectomy in select elderly patients with bladder cancer. J. Urol., 167: 13251328,2002

9- STROUMBAKIS N., HERR W.H., COOKSON M.S., et al.: Radical cystectomy in the octogenarian. J. Urol., 158: 2113-2117, 1997.

10- LEIBOVITCH I., AVIGAD I., BEN-CHAIMJ, et al.: Is it justified to avoid radical cystoprostatectomy in elderly patients with invasive transitional cell carcinoma of the bladder? Cancer, 71: 3098-3101, 1993.

11-ZEBIC N., WEINKNECHT S. and KROEPFL D.: Radical cystectomy in patients aged $>75$ years an updated review of patients treated with Curative and palliative intent. Br. J. Urol. Int., 95: 1211-1214, 2005.

12- BRADSHAW B.G.G., LIU S.S. and THIRBLY R.C. Standardized perioperative care protocols and reduced length of stay after colon surgery. J. Am. Coll. Surg., 186: 501-506, 1998

13- DI FRONZO A.L., CYMERMAN J. and O'CONNEL T.X.: Factors affecting early postoperative feeding following elective open colon resection. Arch. Surg., 134: 941-945, 1999.

14- BROOKS A.D., MARCUS S.G., GRADEK C., et al.: Decreasing length of stay after pancreatoduodenectomy. Arch. Surg., 135: 823- 830, 2000.

15- BRODNER G., VAN AKEN H., HERTLE L., et al.: Multimodal perioperative management-combining thoracic epidural analgesia, forced mobilization, and oral nutritionreduces hormonal and metabolic stress and improves convalescence after major urologic surgery Anesth. Analg., 92: 1594-1600, 2001.
16- SCHUSTER T.G. and MONTIE J.E: Postoperative ileus after abdominal surgery. Urology, 59: 465-471, 2002.

17- PRUTHI R., CHUN J. and RICHMAN M.: Reducing time to oral diet and hospital discharge in patients undergoing radical cystectomy using a perioperative care plan. Urology, 62: 661-665, 2003.

18- MAFFEZZINI M., GERBI G., CAMPODONICO F., et al.: Peri-operative management of ablative and reconstructive surgery for invasive bladder cancer in the elderly. Surg. Oncol., 13: 197-200, 2004.

19- MAFFEZZINI M., GERBI G., CAMPODONICO F., et al.: A multi-modal perioperative plan for radical cystectomy and intestinal urinary reconstruction. II. Effects, limits, and complications of early artificial nutrition. J. Urol., 176: 945-948, 2006.

20- GHONEIM M., EL-MEKRESH M., EL-BAZ M., et al. Radical cystectomy for carcinoma of the bladder: Critical evaluation of the results in 1,026 cases. J. Urol., 158: 393-399, 1997.

21- BREDIN H., PROUT G., et al.: One-stage radical cystectomy for bladder carcinoma: Operative mortality, cost/ benefit analysis. J. Urol., 117: 444- 447, 1977.

22- KOCH M.O., SECKIN B., SMITH J.A.Jr., et al.: Impact of a collaborative care approach to radical cystectomy and urinary reconstruction. J. Urol., 154: 996, 1995.

23- DIMICK J.B., PRONOVOST P.J., LIPSETT P.A., et al.: Complications and costs after high-risk surgery: Where should we focus quality improvement initiatives? J. Am. Coll. Surg., 196: 671, 2003.

24- ZHAN C., MILLER M., et al.: Excess length of stay, charges, and mortality attributable to medical injuries during hospitalization. JAMA, 290: 1868, 2003.

25- PRUTHI R.S., et al.: Fast track program in patients undergoing radical cystectomy: Results in 362 consecutive patients. J AM. Coll. Surg., 210: 93-99, 2010.

26- CERANTOLA Y., VALERIO M., PERSSON B., et al.: Guidelines for perioperative care after radical cystectomy for bladder cancer: enhanced recovery after surgery (ERAS) society recommendations. Clinical Nutrition, 32: 879-887, 2013.

27- KENNETH I., DAVID A., EVANS E., et al.: Effective outpatient use of polyehelene glycol-electrolyte bowel preparation for radical cystectomy and ileal conduit diversion. Urology J., 41: 1-7, 1988.

28- KOUBA E., WALLEN E., PRUTHI R., et al.: Gum chewing stimulates bowel motility in patients undergoing radical cystectomy with urinary diversion. Urology, 70: 1053-1056, 2007

30- PALUMBO V., GIANNARINI G., CRESTANI A., et al.: Enhanced Recovery After Surgery Pathway in Patients Undergoing Open Radical Cystectomy Is Safe and Accelerates Bowel Function Recovery. Urology Feb., 2018. 


\section{العوامل الهعجلة لإستعادة حركة الإمعاء بعد إستئصال

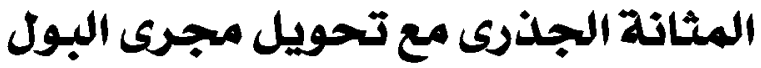

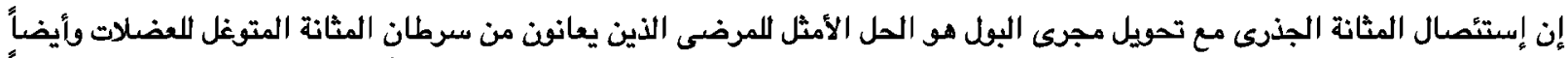

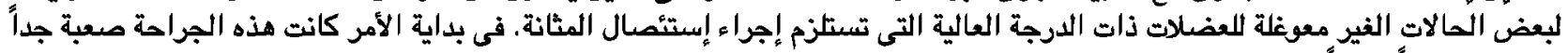

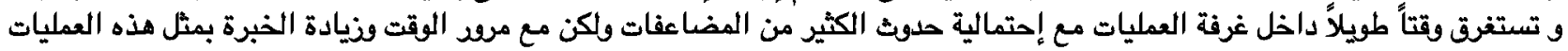

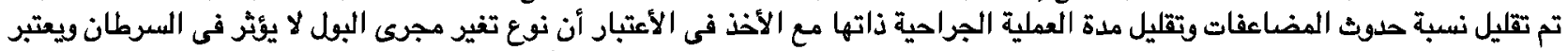

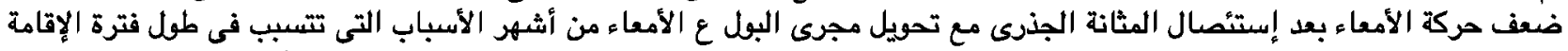

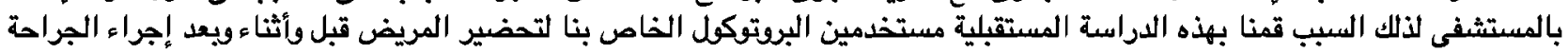

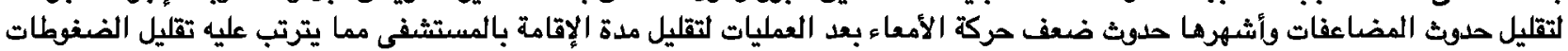

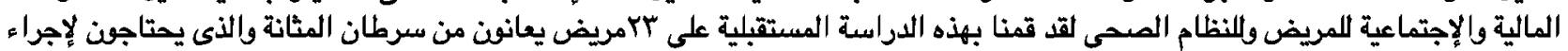

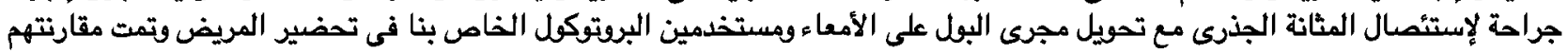

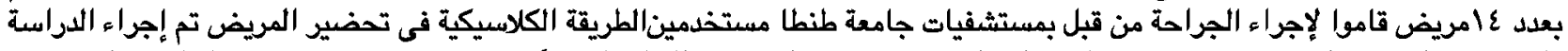

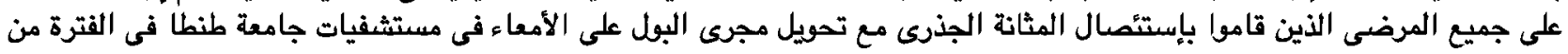

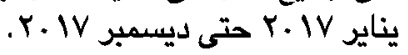

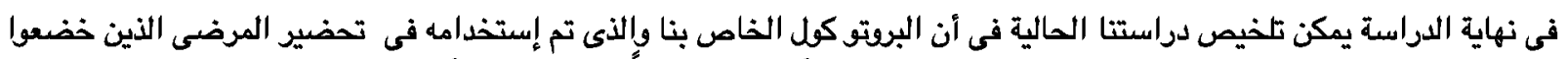

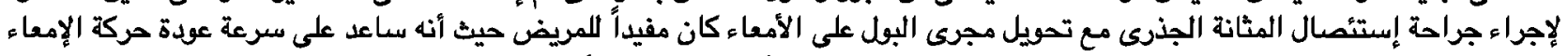

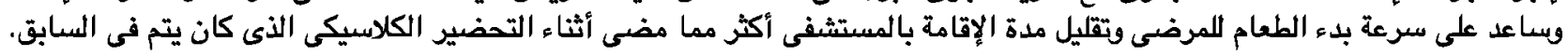

